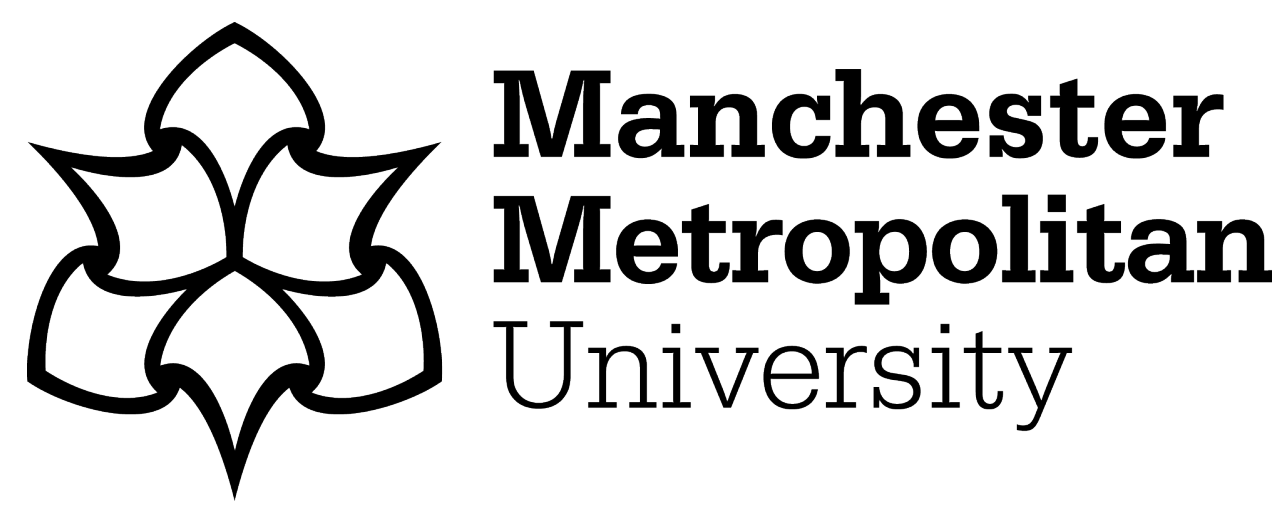

Niedderer, K ORCID logoORCID: https://orcid.org/0000-0002-8188-6338 (2017) Promoting sustainability through mindful design. In: Routledge Handbook of Sustainable Product Design. Taylor \& Francis, pp. 527-539. ISBN 9781138910171

Downloaded from: https://e-space.mmu.ac.uk/624348/

Version: Accepted Version

Publisher: Taylor \& Francis

DOI: https://doi.org/10.4324/9781315693309

Please cite the published version 


\title{
Promoting Sustainability through Mindful Design
}

Kristina Niedderer, University of Wolverhampton, UK

\begin{abstract}
In order to promote sustainability, there is a need for more attentiveness and responsible action towards the environment, which requires changes in perspectives at the levels of both production and use. This chapter provides an introduction to mindful design and its potential to promote sustainability. Based on an analysis of the concepts of mindfulness and mindful design, the paper proposes that mindfulness offers a pertinent means of creating openness to new perspectives, that this can be embedded within design and that, through its use, mindful design offers the potential to instil such attitudes in the user to promote sustainable behaviour. The chapter offers a number of examples in support of this proposition, and to consider the ethical stance embedded in mindful design and its relation to the production and use of mindful design.
\end{abstract}

Keywords: Behaviour change, mindful design, mindfulness, responsible design, sustainability

\section{Introduction: the need for mindful behaviour change}

Environmental sustainability is perhaps one of the most urgent problems we face today. It affects a broad range of issues, including the world's future habitability and its social and economic prosperity (Committee for Climate Change, 2015; IEA, 2015: 3; IPCC, 2015). Environmental problems therefore tend to be interdependent, complex issues that need to be considered in a holistic way. This means sustainable interventions require changing or adapting economic systems and perspectives as well as social attitudes and behaviours (Stern, 2000; Stern, 2006).

Recycling is a prominent example in this regard, which encompasses interventions such as legislation to change behaviour towards resource use, or voluntary commitment by end-users towards preserving resources, or entrepreneurship to develop opportunities for preserving and reclaiming resources that otherwise might go to waste. Such inventions may on the one hand target behaviours of manufacturers to improve product specifications and production patterns for the purpose of reducing energy consumption, waste, $\mathrm{CO}_{2}$ emissions, and to enable the recyclability of all product parts. On the other hand, they may seek to promote a change in user behaviour towards purchasing sustainable materials/goods and towards recycling them to reduce waste and the need for resource mining and by extension reduce $\mathrm{CO}_{2}$ emissions. 
These goals can be promoted through different ways of reinforcement, which either work as incentives or deterrents, and which are either driven by prescription or voluntary engagement (Lockton, Harrison and Stanton, 2010; Niedderer, 2013). For example, legislation is prescriptive. It can work as a deterrent or incentive using taxes, e.g. higher waste tax can be used to incentivise companies to recycle more and waste less and to reduce new resource use and $\mathrm{CO}_{2}$ emissions as a means of working towards set targets for the reduction of greenhouse gas emissions (Crown, 2008). Similarly, the charging of a fee for plastic bottles (e.g. in Germany) ensures the re-turn and re-use of energy rich products.

At the other end of the spectrum, there are voluntary initiatives and social pressures, which are dependent on people's commitments to achieve desired goals, such as recycling banks or centres. Successful voluntary initiatives often go hand-in-hand with legislation, such as in an example of the above mentioned re-use schemes where drinks retailers are forced to take back their bottles (whether glass or plastic), and consumers are incentivised to return them to the retailers. In addition such schemes can offer opportunities for enterprise in facilitating novel ways of re-using or recycling the returned materials.

There are two considerations, which can be drawn from this. Firstly, without the combination of legislation, design innovation and voluntary commitment, this system could not work. This shows that attentiveness to all parts of the system is required if sustainability is to be improved, and a sense of responsibility by all concerned to ensure the implementation of any sustainability initiatives. Secondly, changing a complex system requires a change of perspective to enable a rethinking - and subsequent redesigning - of the system. In the case of recycling, it has required a change from a model of 'cradle to grave' to the 'cradle to cradle' model (Braungart and McDonough, 2010) to establish a system that functions within an equilibrium and that does not exhaust itself.

While leading approaches such as the 'cradle to cradle' model become increasingly well established, their consequent implementation is far from easy, because it requires attentiveness and responsibility on the part of all concerned as well as an ability and willingness to shift perspectives at the levels of both production and consumption.

This chapter proposes the use of mindfulness, and in particular mindful design, as a way of enabling such attentiveness and responsibility and of enabling a change in perspectives and thinking that is conducive to help implement sustainable change. The chapter first discusses the concept of mindfulness and how this can be embedded in mindful design. It then provides a number of examples to demonstrate its application and affect with regard to sustainable 
behaviour. It finally discusses issues of production, use and the ethical stance embedded in mindful design.

\section{Relating design and mindfulness}

Design, loosely understood here as the act of giving form to all human-made things, may be seen to have an ambiguous relationship with environmental sustainability, because of both its material and functional nature.

In terms of its material nature, on the one hand, (mass- and over-) production of design is the cause of many sustainability problems from resource depletion to rising waste mountains. For example, fashion with its fast cycle through the four seasons causes a lot of unsold garments to be destroyed as waste at the end of each season, or garments that have barely been worn by the user to be discarded to be replaced by the latest fashion. How and how often cloths are being washed is also a large factor (Blackburn, 2009, p.3). On the other hand, through sustainable innovation, design can also offer solutions or improvements to existing problems. For example, government backed innovation has led to the development of new, cleaner technologies, such as electric or hydrogen powered cars to reduce $\mathrm{CO} 2$ emissions.

Because of its functional nature, design has found its way into all corners of our daily lives. Its ubiquity and functionality entails that it directs and influences our actions mostly without us noticing, leading to adapting our behaviours to it and causing behavioural change at every level (Niedderer, 2017). For example, the use of a car will allow us to move more flexibly, perhaps to go to work further away from our home, visit friends, go shopping etc.

Unthinkingly, we will surrender to its use where we could perhaps choose another means, such as public transport or cycling, that might potentially be cheaper, more efficient to reach our destination, and more environmentally friendly.

The above examples indicate that the functional nature of design is not neutral and that it requires responsible decision-making on the part of both the designer (and all that are concerned in the production management and process) and the user. The first are required to consider whether and what designs should go into production, whether any design should adhere to the cradle to cradle model, or whether economic gain is the priority. With regard to the latter, Jelsma posits that designers should take moral responsibility for the actions that take place as a result of human interactions with artefacts, intentional or not, because:

'Artefacts have a co-responsibility for the way action develops and for what results.

If we waste energy or produce waste in routine actions such as in household practices, that has to do with the way artefacts guide us' (Jelsma, 2006, p222). 
However, Jelsma's view is not offering a complete picture: while the design of any product may be seen as the designer's responsibility, it is in the user's responsibility to decide whether to purchase any product, when and how to use the acquired product and to what end. For example, it is the end-user's decision how often to buy new clothes, how frequently to wash and wear them and how long to keep them. Similarly, it is the user's decision every day whether to walk, use their car or bike, or the train to go to work. Furthermore, the user has the freedom to decide what to do with any product, and often this may not be an intended function at all. For example, a bike can be used for travelling, but connected to a dynamo it can also be used to generate light or electricity, or it could be used to operate a pump, or parts of it could be used to support a tree or as a weapon. The latter uses are not generally envisaged in the design of a bike, but they are no less possible than the first. It is important to acknowledge this freedom of use, and misuse, on the part of the user. Indeed the difficulty to predict users' actions is regularly acknowledged (e.g. Tromp, Hekkert and Verbeek, 2011), and it is important to recognise that there are a number of factors that determine the decisionmaking process of the user.

The question is how to facilitate intentional sustainable change, and how designers can contribute to it through the products they design? This questions arises if we acknowledge the need for both designers and users to take responsibility for the products they create and their actions with them, but also the difficulty of directing the user's actions.

Generally, design for behaviour change (e.g. Lockton, Harrison and Stanton, 2010, Tromp, Hekkert and Verbeek, 2011) distinguishes different ways of doing so, which can be defined into two pairs of principles to influence human behaviour through design: firstly, through physical influence, which can be either enabling or constraining and, secondly, through psychological influence, which can act as either an incentive or deterrent (see Figure 1). Barriers at a pavement that will prevent drivers physically from driving onto or parking on the pavement are an example of constraining (or prescriptive) design, while traffic lights work as a psychological deterrent through communicating a legal prohibition of crossing them when they show a red light. Many designs also use a combination of these. 


\begin{tabular}{l|l|l} 
& $\begin{array}{l}\text { Positive influence: } \\
\text { promoting behaviour }\end{array}$ & $\begin{array}{l}\text { Negative influence: } \\
\text { restricting behaviour }\end{array}$ \\
\hline $\begin{array}{l}\text { Physical } \\
\text { mechanisms }\end{array}$ & enabling & constraining \\
\hline $\begin{array}{l}\text { Psychological } \\
\text { mechanisms }\end{array}$ & incentive & deterrent \\
\hline
\end{tabular}

Figure 1: basic design mechanisms for enabling behaviour change

These mechanisms, which can be utilised in designing specific products and their actions, are mainly directed towards the action intended by the designer. This area is fairly well researched by now. Although less well researched, it is no less important to pay attention to the motivation of the user (Lockton, Harrison and Stanton, 2010), which may direct any unintended or aberrant action of the user with a product.

While designers have little chance of foreseeing every possible use or action an end user may have with an object, what they can do is to raise the user's awareness of the possible actions with the object to encourage reflection to encourage responsible action. In other words, designers can create mindfulness of the user's actions with the product and of the consequences these actions have on themselves, on others and on the natural environment.

Mindfulness has been defined in different ways. This research follows the Western psychological tradition of mindfulness (Langer, 1989, Langer and Moldoveanu, 2000a, b) in which mindfulness is understood as the process of creating awareness and attentiveness 'to bring one's full resources to a cognitive task by using multiple perspectives and attending to context, which creates novel ways to consider the relevant information.' (Luttrell, Briñol and Petty, 2014, p258).

For example, a person routinely commuting to work by car, when confronted with the proposition to lead a more sustainable lifestyle, if mindful might reconsider how they travel to work, perhaps instead deciding on a combination of walking and taking the train. They might look at the bigger picture seeing that walking will not only reduce $\mathrm{CO}_{2}$ emissions, but at the same time can increase their exercise and improve their health. In this way, the change in life style is seen to provide an opportunity to improve one's lifestyle and responsible behaviour overall. By contrast, a mindless person might continue to drive to work, and decide to go to 
the gym once a week also taking the car, thus adding an extra journey while getting exercise rather less frequently.

However, the state of mindfulness is elusive (Langer, 1989, pp2-9), because it requires breaking through established patterns of experience and preconception (Langer 1989, pp1942). Traditionally, meditation and education have been used to disrupt these patterns and to open them to (re)inspection to create mindful awareness (Langer, 1989, pp81-114; Udall, 1996, p107). However, this makes mindfulness reliant on specific contexts, which are not generally available in everyday life. Design can offer a valuable alternative here, because it is available in everyday contexts. Furthermore, recent studies on computer-supported mindfulness found that appropriate design interventions can significantly surpass the efficacy of traditional mindfulness training (e.g. Chittaro \& Vianella, 2013).

In the following section, I will discuss how mindfulness can be embedded within product design as 'mindful design' to facilitate mindful sustainable behaviour change.

\section{Mindful design and how it works}

In extension of the above definition of mindfulness, mindful design - as the integration of mindfulness into design - refers here to a design's quality to enable the awareness and attentiveness of a person (user) towards the product they are interacting with, towards their (physical, social, experiential etc.) environment and towards the consequences of their actions with the product.

Mindful design can be seen as a useful tool to address and promote sustainable behaviour change, because it addresses the four key factors of sustainable behaviour change: attitude, external context, personal capability and habit/routine (Stern, 2000, p416).

- Attitudinal factors, according to Stern, include norms, beliefs and values.

- Contextual factors include interpersonal influences (e.g. persuasion); community expectations and public or interest group pressures; government regulations, policies or other legal and institutional factors; monetary incentives and costs; advertising; and capabilities and constraints in dealing with things or one's environment.

- Personal capabilities include the knowledge and skills required for particular actions, general capabilities and resources such as literacy, money, and time; as well as sociodemographic variables such as age, educational attainment, race, social status and power. 
- Habit/routine is important because "behavior change often requires breaking old habits and becomes established by creating new ones (Dahlstrand \& Biel, 1997). Habit, in the form of standard operating procedure, is also a key factor in environmentally significant organizational behavior.' (Stern 2000. p416).

Mindfulness, and by extension mindful design, addresses all four criteria. It draws attention to and induces reflection of one's pre-conceptions, one's own actions including routines and habits, and the external context (Langer, 1989). Mindfulness thus allows (re-)considering one's habits/routines and inherent attitudes in relation to the wider context, and in turn to reassess one's personal capabilities for change in any given context. In the following, I discuss how mindful design works and how the four factors are practically embedded within it.

Mindful design is based on two key principles, or stages. It first needs to create awareness of an action (or use) to be reflected on, and then it needs to direct this awareness towards the content of this action and offer potential alternative perspectives or solutions. The first process is called a 'disruption' the second a 'thematisation' (Niedderer 2007, 2014).

The process of disruption is based on the fact that our attention is drawn to what we are doing if an object does not perform exactly the way we expect it to (i.e. if the expectation or efficiency of the interaction with the object is broken in some way). This process is connected to an object's functionality. Function can be disrupted on either practical or symbolic levels, or both. For example, the disruption of the practical function is used regularly as part of safety features, such as warning notices on computers (e.g. when closing a document without having saved it (see Figure 2)). The computer here briefly disrupts our action through a security banner, which requires an additional action to complete the command (e.g. 'save/don't save/cancel'), thus raising our awareness. Similarly, symbolic function can be used to raise the user's attention, as in the example of the shower tiles where the tiles discolour after about three minutes, reminding the user that they should limit their shower to save water and energy (Lagerkvist et al, 2012). In this case, there is no physical barrier to prevent the user to continue showering, but the discolouration is a subtle symbolic cue of their detrimental impact on the environment. The cue utilises the metaphor that showering for too long is damaging the natural environment, symbolised by the disappearing of the decoration on the tiles). 


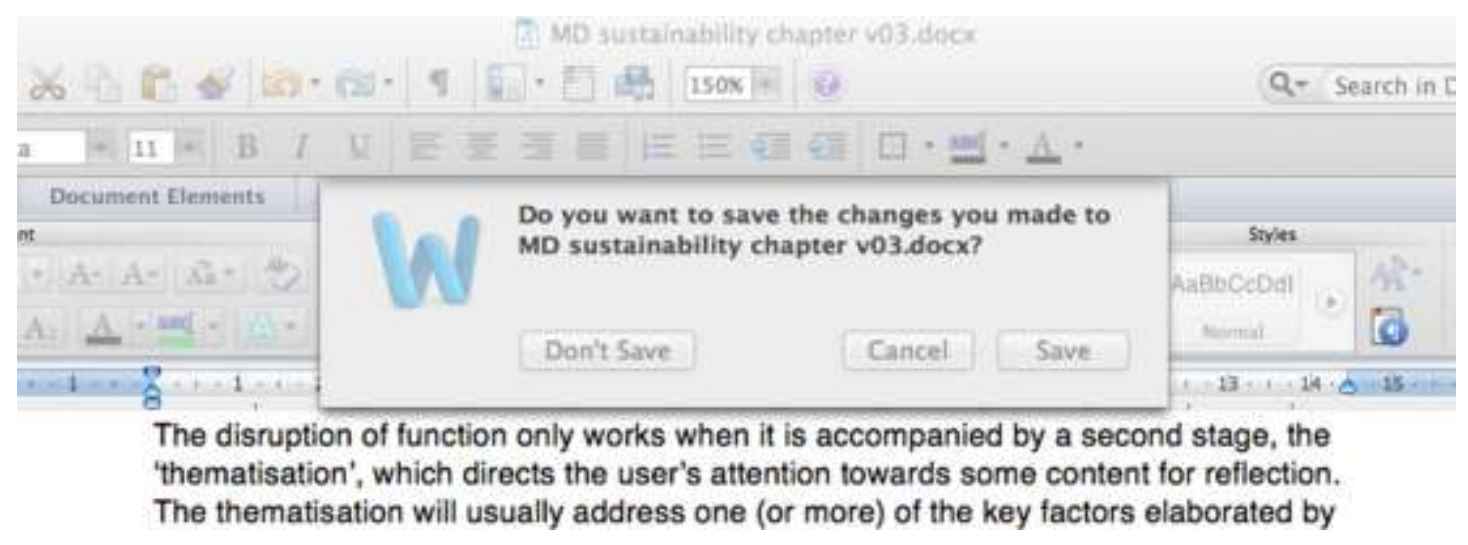

Figure 2: Safety Feature

The disruption of function only works when it is accompanied by a second stage, the 'thematisation', which directs the user's attention towards some content for reflection. The thematisation will usually address one (or more) of the key factors elaborated by Stern (i.e. attitude, external context, or habit/routine), and it must connect with or provide the solution to the disruption. In the case of the safety feature of the computer operating system, the pop-up 'save/don't save/cancel' banner interrupts our routine, and the sentence on the banner and the associated options for resolution constitute the thematisation, that is, the sentence explains why the process in question has been interrupted, and it offers different buttons to proceed to the desired solutions. In the case of the shower tiles, where the symbolic function is used, instead of the practical function (showering/water flow) being interrupted, a related feature is interrupted (tile pattern disappears) which holds a clear symbolic meaning related to the practical action.

The availability of different solutions is important, because they offer choice, and choice in turn requires conscious reflection on the different options available (Langer, 1989, p123) leading to mindful reflection. In line with Stern's key factors, this may include a heightened awareness to:

(1) a greater sensitivity to one's environment, (2) more openness to new information, (3) the creation of new categories for structuring perception, and (4) enhanced awareness of multiple perspectives in problem solving. (Langer and Moldoveanu, 2000a, p2).

However, there will be a practical limit of how many choices can be combined in one object. While adding more choices can increase reflection and thus mindfulness, too many options can make a product potentially confusing to use (Norman 2002, pxii). Therefore, it is 
important to maintain a balance between clarity of message and number of choices appropriate to the context of application, if we are to avoid overwhelming users.

In addition to content and choice, the thematisation can offer different (levels of) meaning, adding complexity as a way of questioning established concepts. For example, a mindful object might raise reflection on the level of the immediate action, such as the computer safety feature or the shower tile. However, if designed differently, the design of the shower tiles could have further levels of meaning. For example, they could also direct the user's attention to issues of hygiene in that the discolouration could also show stains if not cleaned regularly.

The thematisation thus has three 'mechanisms' or 'features' to guide the user's awareness, which comprise content, choice and complexity (Niedderer 2014, pp348-353; Figure 3). These three features need to address one or more of Stern's key factors, including attitude, external context, or habit/routine. In addition, through offering multiple (novel) choices and perspectives, the thematisation should offer the user a new outlook on their personal capabilities.

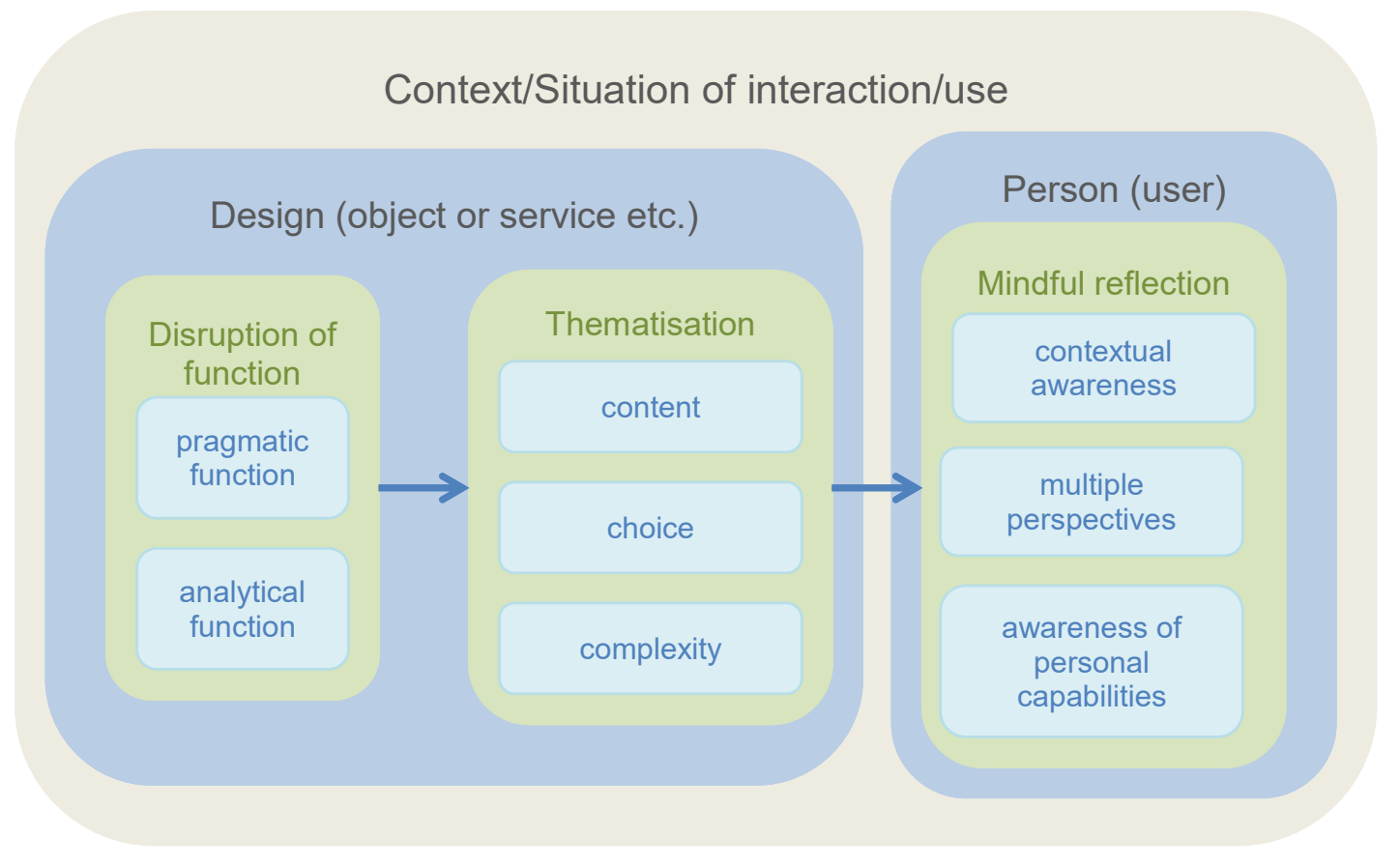

Figure 3: Mindful design mechanisms

The final point, which is of importance here, is the role of emotions. Mindless behaviour regularly tends to be driven by emotions (Niedderer, 2014, pp354-357). In the case of sustainability, often this may be feelings of comfort. Such feelings may lead us to use the central heating more to feel comfortably warm, take a bath to relax instead of taking a shower, 
or use a car instead of cycling or walking to avoid extraneous activity. Emotions guide our lives constantly, and often they make us feel incapable (or unwilling) to change accustomed behaviours. They constitute a complex system of 'survival instincts' that influence our judgment without requiring conscious decision-making and guide our physiological, experiential and behavioural activity in response to survival-related problems and opportunities (Keltner and Ekman, 2000, p163). Because they don't require deliberate decision making, they open the door to mindlessness and promote a singular perspective. For example, an emotional response established as appropriate in one situation may be unthinkingly transferred to a new situation where it might be entirely inappropriate. For example, using one's car for a two-hour journey may be appropriate, but taking it to go to the corner shop which is two minutes away to buy some bread could be considered inappropriate.

While emotions can lead to mindlessness, at the same time they can be used as an incentive to enhance mindful design (Niedderer, 2014, p356) because it is possible for opposing emotions to cancel each other out. For example, positive emotions can partially overlay or cancel out negative emotions (Cohn et al, 2009, p8). In the case of the shower tiles, potentially negative feelings about having to curtail one's shower might be offset by the satisfaction of doing something good to protect the environment. In this way, they can be useful to increase perceptions of personal capabilities and thus support the options for personal capabilities and action offered through the thematisation.

\section{Designing for mindful sustainability}

Having discussed the need for behavioural change, the role of mindfulness in stimulating behaviour change, and how design can enable or support mindful change, this final section will look at the application of mindful design in the context of sustainability.

Over the last two decades, as the spotlight on sustainability has grown and with it the awareness of sustainability, designers have increasingly sought to facilitate behaviour change. By now, a large number of design innovations have emerged with the aim to promote sustainable behaviour. Many of these are focused either on policy, on technological advance, or on service design (e.g. Crocker and Lehmann, 2013; Fuad-Luke, 2009; Bhamra et al, 2011; Dusch, Crilly and Moultrie, 2011). For example, consumer aids to promote sustainable behaviour and consumption in the house include displays to inform about energy or water use, some in form of meter displays, others in form of electrical cords that change colour to alert the user, etc. Yet others include sensor driven devices that switch off light in rooms or heating when not used. What most of these designs have in common is that they either function 
automatically, or they raise attention, but without the requirement for active reflection and response.

Among the various approaches to sustainable product design, solutions of mindful design have also begun to emerge, some of which will be discussed in the following. Interestingly however, compared to other design areas, such as safety or social design, there seem to be as yet comparatively few mindful design solutions for sustainability. The following discussion will therefore not only introduce some examples of sustainable mindful design, but also elicit problems and opportunities of mindful design in the context of sustainability, and consider how its use in promoting sustainable behaviour change could be extended. The discussion will focus on three specific areas of sustainable behaviour change: energy and water consumption in the home, energy consumption and $\mathrm{CO}_{2}$ emissions within personal transport (cars), and issues of waste reduction and recycling.

\section{Sustainable consumption in the home}

This first set of examples is concerned with energy and water consumption in the home. Most houses have electricity and water meters, and usually the heating system is controlled with some kind of thermostat to regulate the temperature. There are also novel interventions, such as smart home heating systems, which can be operated remotely and are slowly coming into use (e.g. Egan, 2014), or meters from solar or wind energy home systems, which provide information about the differential between energy generated and energy used (Letrendre and Taylor, 2009). These kinds of interventions are designed to provide information to the user about their energy or water use. They tend to be supported by educational information, but rarely offer direct nudges to the user as in the example of the shower tiles or safety feature discussed above, even though some simple visual and/or audio solutions might be integrated (e.g. drawing the users attention to the temperature, to the duration of heating cycle etc).

Another example in the household, which relates to water consumption, is the lavatory cistern, for which countless water saving mechanisms have been developed over the years. Usually, they either feature two buttons, a larger indicating larger water consumption and a smaller one for smaller consumption, or a large flip-button, which when pressed at the lower end releases water and when pressed at the upper end stops the water again. This thinking brings us some way towards mindful design in that it provides choice, but not fully because there is no 'disruption' to raise the user's attention and that would require a deliberate action as in the example of the computer safety feature discussed above. Indeed, the idea underlying the safety feature could be transferred into this context. For example, if there was a single button that, when pressed did not initialise the flush but instead revealed the two-button option, then 
the first step would aid raising awareness of the choice that followed and therefore promote more conscious decision-making at the second stage. There are many more areas in the house where such mindful design solutions could provide useful reminders for water or energy saving such as washing machines and tumble driers, kettles, ovens and fridges, for example.

\section{Sustainable considerations for personal transport}

The second area for discussion is concerned with personal transport. The discussion is divided into two parts; firstly, the reduction of car use, and secondly, the reduction of fuel consumption when using a car.

By now, there have been many different attempts at encouraging cycling over driving, using various different means. Urban cycling schemes (e.g. CityBike, 2015) seek to encourage cycling simply through ready access and increased availability (enabling mechanism). Cycling mentor schemes use dedicated cyclists to encourage non-cyclists to take up cycling by joining them and supporting them with route guidance and other forms of constructive input (enabling mechanisms + motivating support) (Wunsch et al, 2015). While both examples have found more or less wide reception, they both rely on the prior commitment of the user to use their bike. Therefore, the decision-making moment at home is clearly the most crucial point for deciding which mode of transport to use. One experimental design, which can be classed as mindful design, is addressing this critical point of decision-making. It is predicated on the use of keys to use and lock the car and bike. The design is a 'key-board' on the wall where both keys are kept. In the design, the keys are weighted such that when choosing the car key the bike key will fall off (but not vice versa) to make the user reflect about using their bike while they pick up the bike key (Laschke et al, 2014). (Figure 4).

Figure 4: Keymoment. Designed by Matthias Laschke and Marc Hassenzahl, reproduced with permission from Matthias Laschke \& Marc Hassenzahl, Copyright 2015

In this design, the practical function and expectation that a key board should safely hold keys is disrupted, and the attention is drawn to a specific content: to the key and its purpose, to cycling, because of the bike key having to be picked up. This actively puts the choice before the user: cycling or driving? The design thus pits personal emotions (comfort of driving) versus social good ('save our earth') combined with more personal effort. In this scenario, reservation (negative emotion) to the latter might be overcome by satisfaction (positive emotion) about oneself in doing something for one's health at the same time. 
The authors also consider the question of emotional 'friction' because of the factor of having to pick up the keys from the floor is likely to be annoying to most people. While this is of course intentional, it shows that the 'disruption' has to be chosen and designed very carefully to provide an (emotional) balance between disrupting/attention raising features and their perceived benefits, because it is likely that mindful designs with less intrusive or annoying disruptive features might ensure a longer-lasting use than ones that create too much annoyance. The author's have therefore considered solutions to give the user a 'break', e.g. by putting the keys on top of the board (Figure 5). An alternative solution might have been to offer a visual or audio response (e.g. traffic light, or image/message reminder), thus making use of a symbolic disruption instead of a disruption of the practical function.

Figure 5: Keymoment - have a break. Designed by Matthias Laschke and Marc Hassenzahl, reproduced with permission from Matthias Laschke \& Marc Hassenzahl, Copyright 2015

Beyond influencing the initial decision making process, there is also the option of raising the awareness of the driver of their fuel consumption. While this is less effective than not using one's car, it can still contribute to a more sustainable (and possibly safer) driving style. Modern cars already have a number of mindful features designed into them. However, they usually pertain to the driver safety rather than to fuel consumption or $\mathrm{CO}_{2}$ emissions. For example, in many $\operatorname{cars}^{1}$, a dashboard light will indicate to the driver if they have not yet fastened their seatbelt, and in some it might actually prevent them driving. Another safety feature in modern cars is the dimming of the dashboard controls when the light levels get low to remind the driver that they ought to switch on the car's headlights. This cue is fairly subtle, but effective, making the display more difficult to read until the headlights are switched on, at which point the display reverts to its normal brightness. In terms of consumption, while modern cars have display features that can be called up to show average consumption when travelling, there is not yet an equivalent to the above mentioned safety features even though it is easily imaginable that the display could offer a reminder when going beyond a certain level of consumption. Similarly, some cars offer different drive-style features that can be selected, including automatic, sport and economic drive modes. Here the choice feature that could underpin a mindful design feature is already available, but there is no mechanism (disruption) yet to remind the driver upon starting a journey to reflect on which feature to chose. Again, such an alert would be easy enough to add as a feature, and could also contribute positively to the overall experience of driving.

\footnotetext{
${ }^{1}$ Specifically, the examples provided here are drawn from an Audi A3, 2015 registration.
} 


\section{Waste reduction, waste collection and recycling}

Besides energy saving measures, the preservation of resources and the reduction of waste are a key issue of product design and manufacture. Over the past three decades or so, legislation, education and voluntary work have contributed to building an extensive system, the consumer facing end of which includes bins for separating out bio-waste, recyclable materials, endwaste, etc., recycling banks, and recycling centres. One of the remaining challenges of this system is the difficulty of consistent voluntary commitment and separation which, if not observed, causes difficulties at the recycling stage leading to inferior produce (EEA, 2005, 2014). In glass recycling for example, this leads to glass cullet where colours are mixed and therefore colour standards cannot be upheld, especially for clear glass, or where there are other contaminants entering the process and which are difficult to remove (WRAP, 2008).

Waste collection and recycling is also a field where mindful design solutions have yet to emerge. Existing solutions such as recycling bins for different materials are clearly useful. However, they suffer from the aforementioned problems of either not being used at all, or of being used at random (Tromp, 2013). Given the importance of these issues, it may be worth considering how powerful examples of mindful design can be transferred into such unexplored product design contexts and scenarios. For example, the mechanism used in the computer safety feature which could be applied to a specific situation or product, such as a recycling bin reminding the user of the eligible content.

\section{Conclusion}

This chapter has discussed the urgent need for more sustainable action and behaviour. It has briefly explained the key mechanisms of behaviour change and their application within design, as well as the role and benefit which mindfulness can have in promoting sustainable behaviour change. The chapter has then explained how design can be used to instil mindful behaviour change. It has illustrated the idea of mindful design through a number of examples from sustainable design as well as safety design to explain the transformative role mindful design can play in the development of everyday product design solutions.

The conclusion of this review of mindful design in the context of sustainability is that mindful design is not yet widely recognised. To address this shortcoming, the above discussion has offered some existing mindful design examples and pointed to several areas of sustainability where mindful design could be applied to beneficial effect. There are also some powerful examples emerging with regard to social, health and safety interventions, which could offer further guidance for the development of mindful sustainable design solutions (Niedderer, 2017). One of the most striking current examples comes form a crossover of the social and 
safety context. It is the example of a traffic junction in Drachten, the Netherlands, (Webster, 2007). This junction had a very high incident rate, which was not improved by further signage. Adopting the shared space model, the traffic planners finally took away all signs, creating a 'shared social space' where each road traffic participant (including pedestrians, cyclists and cars) has equal rights, and which improved the traffic safety of the junction significantly. The design works because the removal of the expected traffic guidance (disruption of expectation) causes individuals to take note of their social context (awareness), and by doing so it requires them to take responsibility for their actions as well as their own safety, thus creating a safer traffic environment overall. This model has by now been transferred to many other crossings in the UK and elsewhere, including junctions in London and Coventry.

One of the reasons why mindful design has not yet been adopted more strongly in the context of sustainability might be because it is strongly predicated on the material nature of design and its production. Like many other sustainable solutions, mindful design solutions inherently take a strong ethical stance. This ethical stance, which acknowledges the need for change and for taking on responsibility, needs to be adopted by designers and manufacturers to promote the development of mindful design solutions. It is my hope that this chapter offers a contribution for all concerned to adopt a sustainable ethical stance.

\section{References}

Bhamra, T.A., Lilley, D. and Tang, T. (2011) 'Design for Sustainable Behaviour: Using products to change consumer behaviour', The Design Journal, vol 14, No 4, pp427-445 Blackburn, R.S. (2009) Sustainable textiles - Life cycle and environmental impact. Great Woodhead Publishing, UK

Braungart, M., and McDonough, W. (2010) Cradle to Cradle: Remaking the Way We Make Things. North Point Press, US.

Chittaro, L. and Vianella, A. (2013) 'Computer-supported mindfulness: Evaluation of a mobile thought distancing application of naive meditators', International Journal of HumanComputer Studies, vol 72, pp337-348

CityBike. (2015) Homepage. https://www.citybikeliverpool.co.uk/info.html

Cohn, M. A., Fredrickson, B.L., Brown, S.L., Mikels, J.A. and Conway A.M. (2009)

'Happiness Unpacked: Positive Emotions Increase Life Satisfaction by Building Resilience', Emotion, vol 9, No 3, pp361-368 [preprint accessed 29 April 2012 from URL: http://www.ncbi.nlm.nih.gov/pmc/articles/PMC3126102/pdf/nihms-222302.pdf ] Committee for Climate Change. (2015) Progress in preparing for climate change: 2015 Report to Parliament. Committee on Climate Change, UK. URL: 
https://www.theccc.org.uk/wp-content/uploads/2015/06/6.736_CCC_ASC_AdaptationProgress-Report2015_FINAL_WEB_250615_RFS.pdf

Crocker, R and Lehman, S. (2013) Motivating Change: Sustainable Design and Behaviour in the Built Environment. Routledge, UK

Crown, (2008). Climate Change Act 2008. Chapter 27. The Stationary Office Limited, UK

Dahlstrand, U. and Biel, A. (1997) 'Pro-environmental habits: Propensity levels in behavioral change', Journal of Applied Social Psychology, vol 27, pp588-601

Dusch, B., Crilly, N. and Moultrie, J. (2011) 'From Attitude to Action: The Development of the Cambridge Sustainable Design Tool Kit', Proceedings of CADMC. University of Cambridge, Cambridge, (no page numbers).

Egan, M. (2014) 'Heat Genius review: smart home heating system can save you money, will keep you warm - and it's wireless', TechAdviser, 27 Oct 2014. URL:

http://www.pcadvisor.co.uk/review/smart-thermostats/heat-genius-review-3582552/

EEA. (2014) Recycling rates in Europe. European Environmental Agency, Luxembourg.

EEA (2005) Effectiveness of packaging waste management systems in selected countries: an

EEA pilot study, Office for Official Publications of the European Communities, European

Environmental Agency, Luxembourg

Fuad-Luke, A. (2009) Design activism: Beautiful strangeness for a sustainable world, Earthscan, UK

IEA (2015) Energy and Climate Change, International Energy Agency. URL:

https://www.iea.org/publications/freepublications/publication/WEO2015SpecialReportonEner gyandClimateChange.pdf

IPCC. (2015) Climate Change 2014: Synthesis report. Intergovernmental Panel on Climate

Change, CH. URL: http://www.ipcc.ch/pdf/assessment-

report/ar5/syr/SYR_AR5_FINAL_full_wcover.pdf

Jelsma, J. (2006) 'Designing 'Moralized' Products', in Verbeek, P.P. and Slob, A. (Eds), User Behavior and Technology Development: Shaping Sustainable Relations Between Consumers and Technologies, Springer, Berlin , pp221-23

Lagerkvist, S., C. von der Lancken, A. Lindgren, and K. Sävström (2012) Static! Increasing Energy Awareness: Disappearing-Pattern Tiles, Interactive Institute, Sweden. URL:

http://dru.tii.se/static/disappearing.htm

Langer, E. J. (1989) Mindfulness, Addison Wesley Publishing Company, US

Langer, E.J., and M. Moldoveanu. (2000a) 'The construct of mindfulness', Journal of Social Issues, vol 56, No 1, pp1-9.

Langer, E.J., and M. Moldoveanu. (2000b) 'Mindfulness Research and the Future', Journal of Social Issues, vol 56, No 1, pp129-139 
Laschke, M., Hassenzahl, M., Diefenbach, S. and Schneider, T. (2014) 'Keymoment: Initiating Behavior Change through Friendly Friction', NordiCHI '14, Oct 26-30 2014, Helsinki, Finland.

Letrendre, S. and Taylor, M. (2009) SEPA Report: Residential Photovoltaic Metering and Interconnection Study, SEPA. URL: https://www.solarelectricpower.org/discoverresources/publications-and-media.aspx

Lockton, D., Harrison, D., Stanton, N.A. (2010). 'The Design with Intent Method: a design tool for influencing user behaviour', Applied Ergonomics, vol 41, No 3, pp382-392 Luttrell, A., Briñol P., and Petty, R.E. (2014) 'Mindful Versus Mindless Thinking and Persuasion', in Ie, A., Ngnoumen, C.T. and Langer, E. (Eds) The Wiley Blackwell Handbook of Mindfulness, vol 1., Wiley, Chichester, pp258-278

Keltner, D. and Ekman, P. (2000) 'Emotion: An overview’, in Kazdin, A. (Ed) Encyclopedia of Psychology, Oxford University Press, London, pp162-167

Niedderer, K. (2017) 'Facilitating Behaviour Change through Mindful Design', in Niedderer, K., Clune, S. and Ludden, G. (Eds) Design for Behaviour Change. Ashgate, UK

Niedderer, K. (2014) 'Mediating Mindful Social Interactions through Design', in Ie, A., Ngnoumen, C.T. and Langer, E. (Eds) The Wiley Blackwell Handbook of Mindfulness, vol 1., Wiley, Chichester, pp345-366

Niedderer, K. (2013) 'Mindful Design as a Driver for Social Behaviour Change', Proceedings of the IASDR Conference 2013, IASDR, Tokyo, Japan, 27-10 August 2013

Niedderer, K. (2007) 'Designing Mindful Interaction: The Category of the Performative Object', Design Issues, vol 23, No 1, pp3-17.

Norman, D.A. (2002) The Design of Everyday Things. Basic Books, US

SMMT (2015) 2015 Automotive Sustainability Report 16th edition - 2014 data. URL: http://www.smmt.co.uk/wp-content/uploads/sites/2/SMMT-16th-Sustainability-Reportfinal.pdf

Stern, N.H. (2006) The economics of climate change. HM Treasury, UK

Stern, P.C. (2000). 'New environmental theories: toward a coherent theory of environmentally significant behavior', Journal of Social Issues, vol 56, No 3, pp407-424 Tromp, N., Hekkert, P. and Verbeek, P.P. (2011) 'Design for socially responsible behaviour: A classification of influence based on intended user experience', Design Issues, vol 27, No 3, pp3-19

Tromp, N. (2013) Social Design: How products and services can help us act in ways that benefit society (PhD), TU Delft, NL

Udall, N. (1996) An Investigation into the Heuristics of Mindfulness in Higher Art and Design Education (PhD Thesis), University of Surrey, UK 
Webster, C. (2007) 'Property rights, public space and urban design', The Town Planning

Review, vol 78, No 1, pp81-101

WRAP (2008) Refillable glass beverage container systems in the UK, The Waste \&

Resources Action Programme (WRAP), UK

Wunsch, M., Stibe, A., Millonig, A., Seer, S., Dai, S., Schechtner, K. and Chin, R.C.C. (2015)

'What Makes You Bike? Exploring Persuasive Strategies to Encourage Low-Energy

Mobility', in MacTavish, T. and Basapur, S. (Eds) PERSUASIVE 2015, LNCS 9072, pp53-64 